\title{
Investigation into backprop forces and deflections at St George Wharf
}

\author{
R. L. Vollum* \\ Imperial College of Science, Technology and Medicine, London
}

The first part of the paper shows that good estimates of backprop forces are obtainable from the Cardington building if the slab stiffness is reduced to allow for cracking. This is significant since it resolves an apparent inconsistency between the author's work on deflection and Beeby's work on forces in backprops. The second part of the paper investigates the forces in backprops and slab deflections at St George Wharf, London. The work was carried out to investigate the validity of design procedures based on research at Cardington that have been widely disseminated in Best Practice Guides and elsewhere. Measured and predicted backprop forces and deflections are shown to compare well at St George Wharf which increases confidence in the Cardington research. The paper also describes the backpropping arrangement used at St George Wharf for construction of the $600 \mathrm{~mm}$ thick transfer slab at the 15th floor. The backpropping arrangement was designed using the traditional assumption that loads are equally shared between floors since the frame contractor could not justify the design using the improved methods developed by Beeby from research at Cardington. Back analysis shows that the design can only be justified if preload is taken into account in the backprops.

\section{Notation}

C cracking coefficient defined as $C=E_{\text {cused }} /$ $E_{\text {cpeak. }}$ The subscripts top and bottom refer to the top and bottom slabs in supporting assembly respectively

$E_{\text {cpeak }} \quad$ concrete elastic modulus in top slab of supporting assembly when slab above is cast

$E_{\text {cused }} \quad$ concrete elastic modulus used in analysis

$f_{c m} \quad$ mean cylinder strength

$f_{c t m} \quad$ mean concrete tensile strength

$f_{\text {ctmodified }}$ reduced concrete tensile strength for deflection prediction

$K, K_{\min }$ damage parameter used in calculation of $f_{\text {ctmodified }}$

$M_{r} \quad$ cracking moment

$w_{b} \quad$ average load in backprops in $\mathrm{kN} / \mathrm{m}^{2}$

$w_{p} \quad$ average load in props in $\mathrm{kN} / \mathrm{m}^{2}$

$w_{\text {perm }} \quad$ permanent load

$w_{\text {peak }} \quad$ peak construction load

\footnotetext{
* Department of Civil and Environmental Engineering, Imperial College Road, Imperial College, London SW7 2BU, UK.

(MCR 1109) Paper received 8 January 2003; accepted 20 March 2003
}

$\begin{array}{ll}w_{\text {strike }} & \begin{array}{l}\text { load at striking } \\ \beta\end{array} \\ & \begin{array}{l}\text { interpolation coefficient used in MC90 and } \\ \text { EC2 to find mean curvature }\end{array} \\ \phi & \text { creep coefficient } \\ \zeta & \text { interpolation coefficient used to find mean } \\ & \text { curvature } 1 / r_{m} \\ \Delta T & \text { temperature change }\end{array}$

\section{Introduction}

The author ${ }^{1-3}$ has shown previously that long-term deflections in flat slabs at Cardington were governed by cracking at striking or when the slab above was cast. Consequently, the author ${ }^{1-4}$ proposed that a modified concrete tensile strength $f_{\text {ctmodified }}$ should be used in deflection calculations to take account of cracking during construction where $f_{\text {ctmodified }}$ is defined as

$$
f_{\text {ctmodified }}=\mathrm{K}_{\text {min }} w / \sqrt{ } \beta
$$

where $w$ is the load in $\mathrm{kN} / \mathrm{m}^{2}$ and $\beta$ is 1 for first loading to $w$ and 0.5 otherwise. $K_{\min }$ is the minimum value of $K=\sqrt{ } \beta f_{c t} / w$ evaluated at striking, peak construction load and full service load as appropriate. Measurements of backprop forces at Cardington showed that the top slab in the supporting assembly carried 
about $70 \%$ of the load from casting the slab above. Consequently, the author proposed that the peak construction load $w_{\text {peak }}$ should be taken as:

$$
\mathrm{w}_{\text {peak }}=\mathrm{w}_{\text {self }}+0 \cdot 7\left(\mathrm{w}_{\text {self }}+\mathrm{w}_{\text {con }}\right)
$$

where $w_{c o n}$ is a construction load for formwork and access. At Cardington $w_{\text {con }}$ was about $0.75 \mathrm{kN} / \mathrm{m}^{2}$. Equation (2) is applicable for construction load histories similar to Fig. 1 which is from St George Wharf where two levels of backprops were used. It can be seen that the slab carried its self-weight when struck and the peak load occurred when the slab above was cast. The author's conclusion that slabs cracked during construction at Cardington appears inconsistent with Beeby's 5 work on calculating forces in backprops. Beeby concluded that the Cardington slabs did not crack significantly during construction since $(a)$ the total force in the backprops increased in proportion to that in the props during casting and $(b)$ he obtained good estimates of the forces in backprops from an elastic analysis in which slabs were assumed uncracked. Item (a) is inconclusive since it only implies that the stiffness of the slabs in the supporting assembly was constant during casting which is predicted by the author's model $^{2}$ for reasons described below. Item $(b)$ above is similarly inconclusive. Therefore, the author carried out a series of $3 \mathrm{D}$ elastic finite element analyses to determine the influence of slab stiffness on backprop forces in the Cardington in situ concrete building shortly after casting the third, fifth and sixth floors. One level of backprops was used for the construction of these floors and all the arrangements of backprops were symmetrical about the centre lines of the bays with no backprops on lines between columns. Four backprops were placed on a $2.5 \mathrm{~m}$ square grid at the centre of each $7.5 \mathrm{~m}$ square bay during construction of floors 3 and 6 . Nine backprops were placed on a $1.875 \mathrm{~m}$ square grid between floors 3 and 4 during construction of floor 5 . Readers are referred to Beeby ${ }^{5}$ for more details of the layouts of props and backprops. The loads from the props which supported the falsework were modelled both as point loads and as a uniformly distributed load. In each case, the average prop load per square metre was taken as the measured value. Where not measured, prop forces were assumed to be proportional to the area

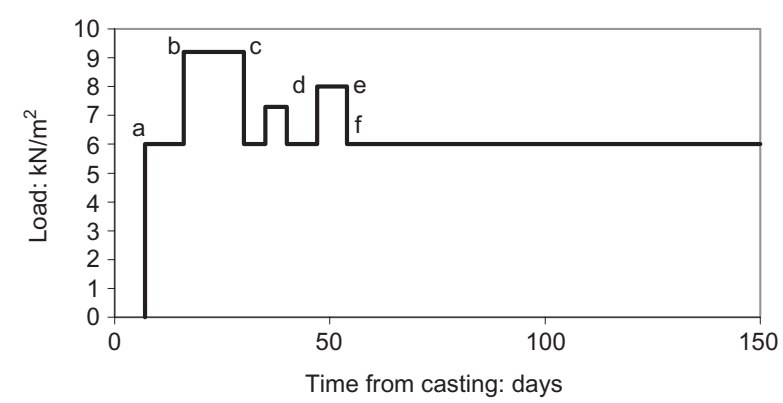

Fig. 1. Load history for St George Wharf enclosed by the centrelines between adjacent props. One quarter of the floor plates were modelled in the finite element analysis. The backprop stiffness was taken as $25 \mathrm{kN} / \mathrm{mm}$ as derived by Beeby. ${ }^{5}$ Theoretically, backprop forces should be determined in a nonlinear analysis that accounts for cracking. In practice, this is complex since the loading history is different for each slab in the supporting assembly. Therefore, the reduction in stiffness due to cracking was modelled by globally reducing the concrete elastic modulus in the slab. An equivalent elastic modulus $E_{\text {cused }}$ was derived for each slab in the supporting assembly from deflections calculated with a finite element program developed by Hossain. ${ }^{2}$ The programme derives mean curvatures using the $\mathrm{MC} 90^{6}$ moment-curvature relationship in which mean curvatures are found by interpolating between curvatures of uncracked (state 1) and fully cracked (state 2 ) sections. The mean curvature is given by

$$
1 / r_{m}=\zeta\left(1 / r_{2}+1 / r_{s h 2}\right)+(1-\zeta)\left(1 / r_{1}+1 / r_{s h 1}\right)
$$

where $1 / r=M / E_{c} I$ for states 1 and 2 and

$$
\xi=1-\beta\left(M_{r} / M\right)^{2} \text { for } M \geqslant \sqrt{ } \beta M_{r}
$$

where $\beta$ accounts for loss of tension stiffening after loading and is taken as 1 for first loading and 0.5 for repeated or long term loading. Recent work by Beeby et $a l^{7}$ and the author ${ }^{3}$ shows that tension stiffening is lost rapidly in cracked sections. There is considerable scatter in the test data but it seems reasonable to assume $\beta$ reduces to about $0 \cdot 7$ in one day as suggested by the author. ${ }^{3} 1 / r_{s h}$ is the shrinkage curvature. Hossain's program calculates deflections immediately after unloading with the Rotilio ${ }^{8}$ method in which the unloading line is assumed to intersect the state 1 (uncracked) line at a moment equal and opposite to that before unloading (see Fig. 2). The reloading line was assumed to follow the unloading line.

Equivalent elastic moduli $E_{\text {cused }}$ were derived for each floor in the supporting assembly from deflections calculated with Hossain's ${ }^{2}$ program (using the incremental procedure described previously ${ }^{2}$ ) as follows:

$$
E_{\text {cused }}=E_{\text {cpeak }} \Delta a_{\text {elastic }} / \Delta a
$$

where $E_{\text {cpeak }}$ is the concrete elastic modulus in the top slab of the supporting assembly when the slab above is cast. $\Delta a$ and $\Delta a_{\text {elastic }}$ are the predicted and elastic (for $\left.E_{c}=E_{\text {cpeak }}\right)$ increments in deflection in the supporting slabs due to due to casting the supported slab. $\Delta a$ was estimated for the top slab in the supporting assembly from deflections calculated immediately before (with $\beta_{\text {strike }}=0.5$ ) and after casting the slab immediately above (with $\beta_{\text {strike }}=0.5$ and $\beta_{\text {peak }}=1 \cdot 0$ ). The analysis predicts that the slab stiffness remained constant during casting (as illustrated schematically in Fig. 2) since $K_{\text {strike }}$ (with $\beta=0.5$ ) is less than $K_{\text {peak }}$ with $\beta>0.65$ for the Cardington slabs. $\Delta a$ was estimated for the bottom slab (e.g. floor 3 when casting floor 5) from 


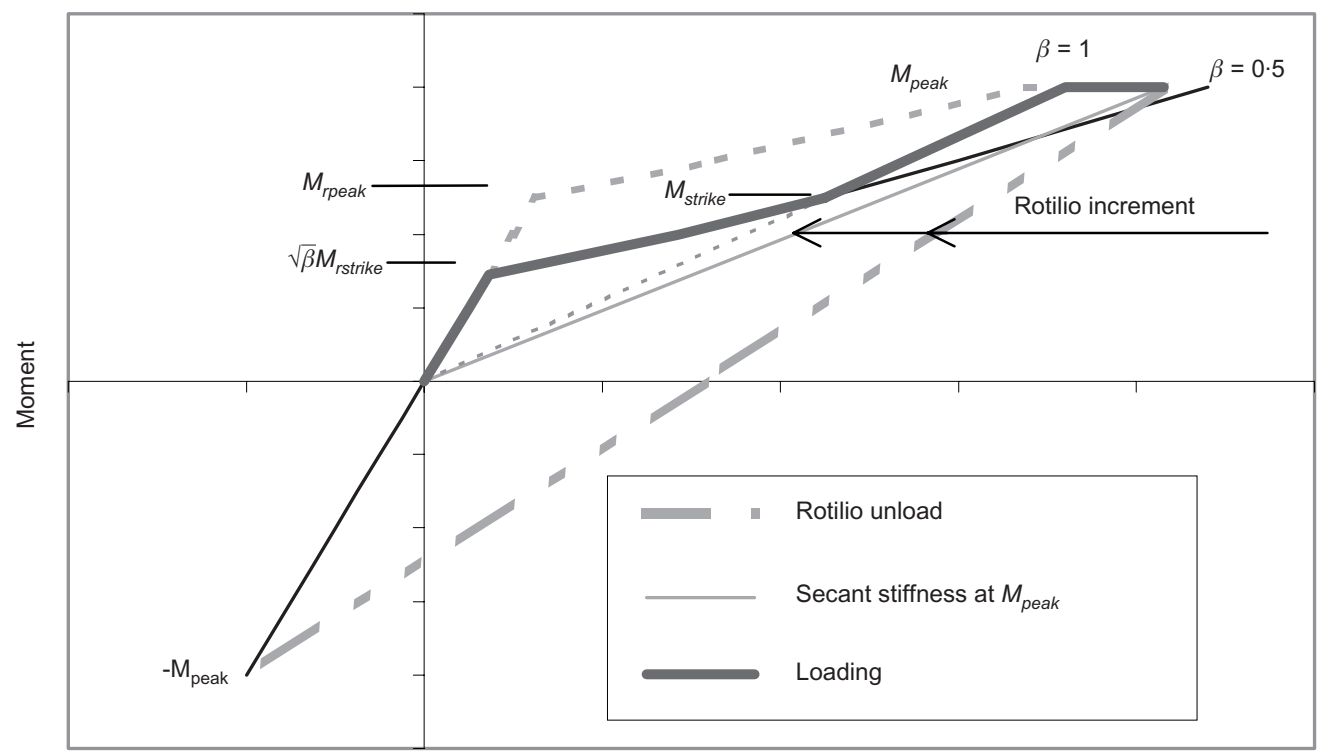

Curvature

Fig. 2. Rotilio increment in deflection (with $\beta=0.5$ for loading to $M_{\text {strike }}$ )

deflections calculated immediately before and after striking the slab immediately above with $\beta_{\text {strike }}=\beta_{\text {peak }}$ $=0 \cdot 5$. $E_{\text {cused }}$ was taken as the average of values calculated at the centre of external and corner panels which were similar. The resulting ratios $C=E_{\text {cused }} / E_{\text {cpeak }}$ are given in Table 1 which shows that $C$ was around 0.6 for each slab in the supporting assembly. Backprop forces were calculated using the reduced elastic moduli $E_{\text {cused }}$ given in Table 1 and were found to agree well with measured forces (with the exception of floor 6) which were reduced by the preload corresponding to zero load in the props (see Table 1). This is significant since it supports the author's conclusion that long-term deflections in the Cardington slabs were governed by cracking during construction. Fig. 3 shows that predicted backprop forces are relatively insensitive to the cracking factor $C$ (if the same for all slabs) and explains why Beeby ${ }^{5}$ obtained good estimates of backprop forces assuming slabs to be uncracked. Fig. 3 also shows that it made little difference to model loads from props as uniformly distributed instead of individual point loads. Unfortunately, it is not possible to show conclusively that the author's analysis is more realistic than Beeby's since deflections were not measured during construction at Cardington.

\section{Slab deflections and backprop forces at $\mathrm{St}$ George wharf}

The second part of this paper describes an investigation into backprop forces and slab deflections at $\mathrm{St}$ George Wharf. Deflections were measured in floors 36 at the locations shown in Fig. 4. All the floor slabs are $250 \mathrm{~mm}$ thick flat slabs with a maximum span of $9 \mathrm{~m}$ between internal columns. The slabs were designed using elastic finite element analysis taking pattern loading into account for a maximum design ultimate load of $13.24 \mathrm{kN} / \mathrm{m}^{2}$. No moment redistribution was carried out. Deflections were measured throughout the construction process in each slab and subsequently. Stephensons (the frame contractor at St George Wharf) made alternate designs for backprops in accordance with (a) BS $5975^{9}$ (which assumes loads are equally shared between supporting slabs during casting higher floors) and (b) elastic analysis using Beeby's ${ }^{5}$ spreadsheet that predicts that the top slab in the supporting assembly carries about $65-70 \%$ of the load from casting the slab above. The total load transferred to the supporting assembly was assumed to be 6 (slab selfweight $)+0 \cdot 5$ (falsework) $+1 \cdot 5$ (construction load $)=$ $8 \mathrm{kN} / \mathrm{m}^{2}$. Following BS 5975, ${ }^{9}$ the peak unfactored

Table 1. Comparison between measured and predicted average backprop loads $w_{b}$ less preload corresponding to zero load $w_{p}$ in the props

\begin{tabular}{l|c|c|c|c|c|c}
\hline Cast slab $i+1$ & $\begin{array}{c}E_{\text {cpeak }} \text { slab } i \\
\mathrm{kN} / \mathrm{mm}^{2}\end{array}$ & $C_{\text {top }}$ & $C_{\text {bot }}$ & Pred/Test & $w_{b}$-preload: $\mathrm{kN} / \mathrm{m}^{2}$ & Preload: $\mathrm{kN} / \mathrm{m}^{2}$ \\
\hline 3 & $31 \cdot 7$ & 0.60 & 0.69 & $1 \cdot 04$ & $1 \cdot 77$ \\
5 & $35 \cdot 18$ & 0.62 & 0.59 & 0.94 & $2 \cdot 05$ \\
6 & 31.35 & 0.54 & 0.60 & 0.93 & $0 \cdot 40$ \\
\hline
\end{tabular}




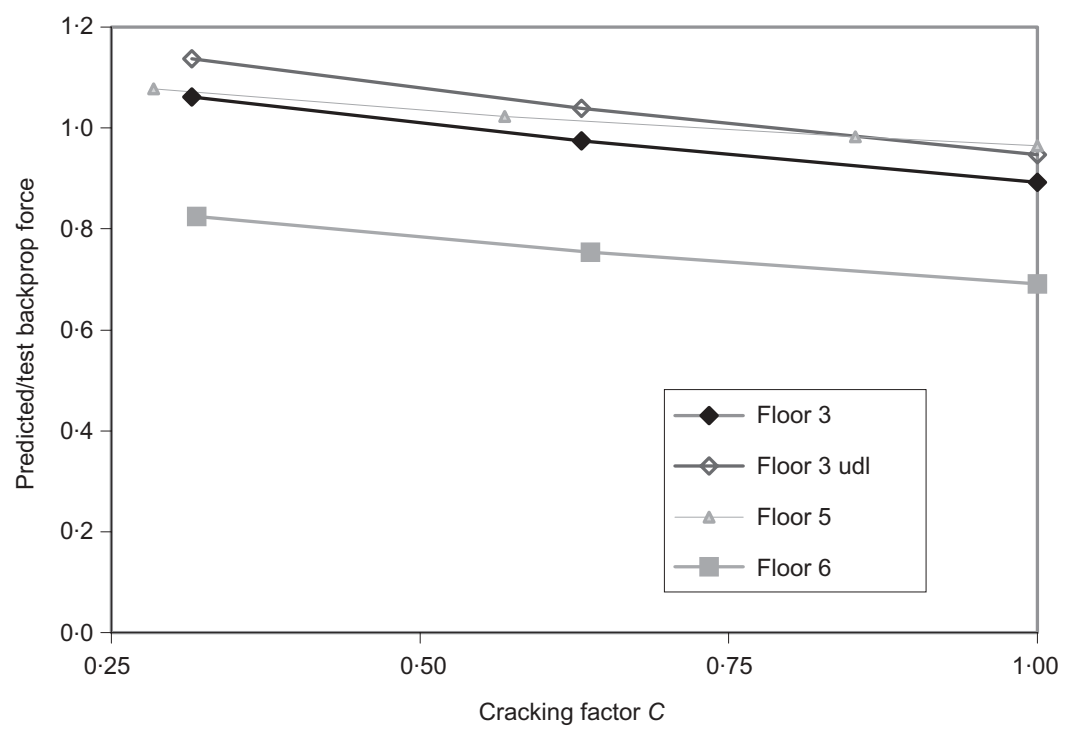

Fig. 3. Influence of cracking factor $C$ on backprop forces from casting floor 3 at Cardington

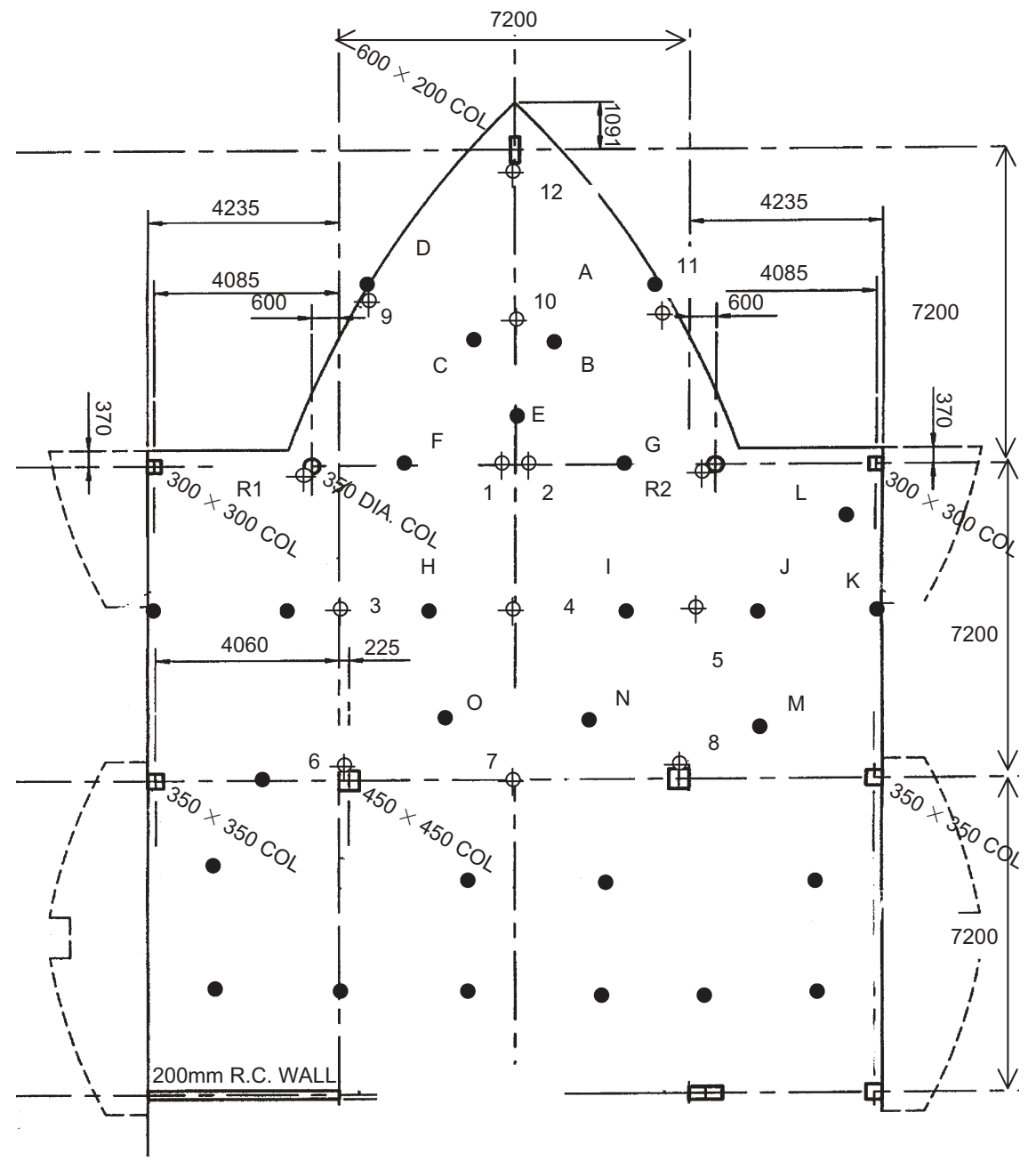

A Backprop position between levels 4 and 5

$\phi_{8}$ Level point

Fig. 4. Area in which deflections were measured at St George Wharf 
design loads in the supporting slabs were calculated to be $10 \mathrm{kN} / \mathrm{m}^{2}$ with one level of backprops and $8.67 \mathrm{kN} /$ $\mathrm{m}^{2}$ with two levels of backprops. These loads were factored by 1.3 and for compliance compared with the slab design ultimate load of $13 \cdot 24 \mathrm{kN} / \mathrm{m}^{2}$. Following Beeby's approach, ${ }^{5}$ the peak unfactored design load was estimated to be $11.28 \mathrm{kN} / \mathrm{m}^{2}$ for one level of backprops which is significantly greater than the unfactored design load of $9 \cdot 1 \mathrm{kN} / \mathrm{m}^{2}$. Stephensons concluded that two levels of backprops were required and justified the design with BS 5975 since Beeby's approach gives no significant reduction in $w_{\text {peak }}$ for two levels of backprops. The exercise showed that there are difficulties in applying Beeby's criteria for casting slabs above to slabs with low design imposed loads unless access loads and factors of safety against collapse are reduced below current practice and peak construction loads are permitted to exceed the unfactored design load. Beeby gives some guidance on these issues. In practice, the flexural capacity of the slabs was significantly greater than the design capacity due to $(a)$ rationalisation of reinforcement and $(b)$ moments were not redistributed. The author believes that slabs should be designed for the peak construction loads given in Table 3 of the Best Practice Guide. $^{10}$

\section{Concrete properties at St George Wharf}

The specified concrete cube strength in the slabs was $40 \mathrm{MPa}$ at 28 days. Concrete strengths were measured with water and air cured cubes and Lok tests in the top of the slab. There was some difficulty in determining the concrete strength in the slabs since strengths from the Lok tests were significantly less ( $\sim 25 \%$ at 7 days) than the corresponding strengths of air cured cubes (see Table 2). The reason for this is not fully understood. On the basis of research at Cardington, ${ }^{11}$ it was anticipated that the strength of the air cured cubes would be less than the Lok test strengths since the temperature was expected to be greater in the slab than in the air cured cubes. This may have not been the case since the majority of air cured cubes were sheltered from the wind in a hut at ground floor level unlike the slabs which were exposed to the high winds which blew off the river Thames. The author ${ }^{3}$ has shown elsewhere that deflections are more influenced by cracking in the soffit (span) than in the top surface (support) which suggests that it is more realistic to use the concrete strength in the bottom surface of the slab in deflection calculations. Research at Cardington ${ }^{11}$ showed that Lok test strengths were on average $14 \%$ greater in the bottom of the slab than the top with a greater difference at early age due to the difference in temperature between the top and bottom of the slab. It is likely that the difference in strength between the top and bottom of the slab was even greater at St George since the Cardington building was constructed in a hanger which sheltered it from wind. Therefore, the concrete strength for deflection prediction is considered to lie between the Lok and air cured cube strengths.

Research at Cardington ${ }^{1}$ showed that concrete tensile strengths could be estimated using equation (6) below which is similar to the equation given in EC2 with $f_{c k}$ replaced by $f_{c m}$

$$
f_{c t m}=0 \cdot 3 f_{c m}^{(2 / 3)}
$$

where $f_{c m}$ is the mean cylinder strength which was assumed to be 0.8 times the cube strength. Concrete tensile strengths (splitting) were measured at Imperial College between 5 and 28 days and were found to be about $5 \%$ less than the values given by equation (6). Deflections depend on the concrete tensile strengths at striking and when the slab above is cast. Analysis of the water cured cube strengths showed that EC2 ${ }^{12}$ predicted the development of concrete strength reasonably well as shown in Fig. 5. Therefore, concrete cube strengths were estimated for deflection prediction at striking and casting the slab above $\left(w_{\text {peak }}\right)$ with the EC2 strength development function for normal concrete assuming the 28 day strength was the average of the strengths from the Lok tests and the water cured cubes. The corresponding cube strengths and tensile strengths corresponding to equation (6) are given in Table 3 . The concrete age was reduced by a factor of $0 \cdot 6$, which was derived using EC2, in the strength development function to account for the low temperatures on site. Fig. 5 shows that this approach is reasonable for floor 3 which was typical.

The concrete elastic modulus, creep and shrinkage were measured in the Concrete Structures Laboratory at Imperial College for concrete from the sixth floor.

Table 2. Concrete strengths (MPa) at St George Wharf

\begin{tabular}{l|c|c|c|c|c|c|c|c|c|c}
\hline \multirow{2}{*}{ Floor } & \multicolumn{3}{|c|}{ Lok test } & \multicolumn{3}{c|}{ Cube air } & \multicolumn{3}{c}{ Cube water } \\
\cline { 2 - 11 } & \multicolumn{3}{|c|}{ Age: days } & \multicolumn{3}{c|}{ Age: days } & \multicolumn{3}{c}{ Age: days } \\
\cline { 2 - 11 } & 3 & 7 & 28 & 3 & 6 & 7 & 3 & 6 & 7 & 28 \\
\hline 3 & $15 \cdot 2$ & $27 \cdot 9$ & $41 \cdot 8$ & $27 \cdot 8$ & - & 37 & 33 & - & $39 \cdot 8$ & $51 \cdot 3$ \\
4 & - & $23 \cdot 6$ & $39 \cdot 1$ & - & 32 & $32 \cdot 5$ & - & $34 \cdot 3$ & $36 \cdot 3$ & $55 \cdot 5$ \\
5 & $18 \cdot 1$ & $29 \cdot 1$ & - & $23 \cdot 5$ & - & $36 \cdot 5$ & 35 & - & 49 & 54 \\
6 & $22 \cdot 3$ & $29 \cdot 2$ & $46 \cdot 6$ & - & - & $22 \cdot 5$ & 27 & - & $33 \cdot 7$ & 54 \\
\hline
\end{tabular}




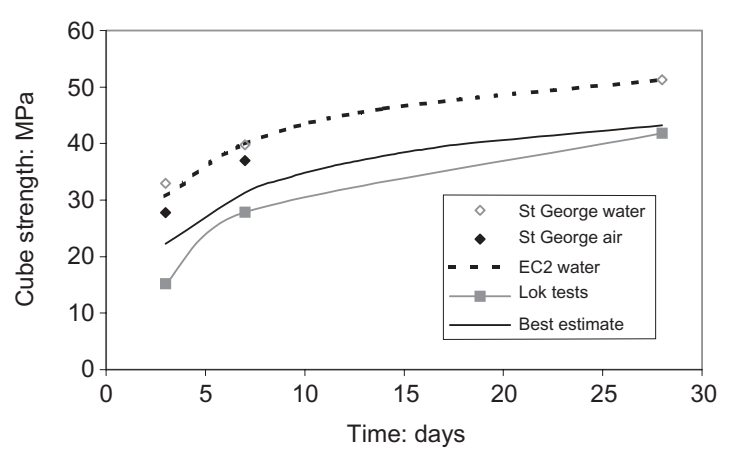

Fig. 5. Comparison of concrete strengths in floor 3

The creep and shrinkage specimens which were 100 $\mathrm{mm}$ diameter cylinders were unsealed. The creep and shrinkage tests were started when the concrete was 5 days old when the concrete cube strength was $26 \mathrm{MPa}$. The mean concrete elastic modulus, $E_{c}$, was $20.5 \mathrm{GPa}$ at the start of the creep tests compared with $27 \cdot 4 \mathrm{GPa}$ given by EC2. Figs 6 and 7 show that the measured creep coefficients and shrinkage strains agree well with those predicted by EC2. The EC2 creep coefficients in Fig. 6 were derived using the measured elastic modulus at loading in conjunction with the EC2 28 day elastic modulus $E_{c 28 E C 2}$ (and then multiplied by $E_{c} / E_{c 28 E C 2}$ to convert them into true creep coefficients).

\section{Comparison of measured and predicted backprop forces at St George wharf}

An investigation was carried out into backprop forces at St George Wharf ${ }^{13}$ to investigate the generality of Beeby's 5 conclusion that prop forces can be predicted from elastic analysis. Strains were measured in 15 backprops between floors 4 and 5 (the labelled backprops in Fig. 4) and 12 backprops between floors 3 and 4 before and after casting floor 6 . The instrumented backprops were located in the same bays that deflections were measured. The layout of backprops between floors 3 and 4 was similar to that shown in Fig. 4 . The props between levels 4 and 5 were aluminium Ischebeck Titan 2 props and those between floors 3 and 4 were steel Acrow props. Strains were measured using a Demec gauge with a $200 \mathrm{~mm}$ gauge length and were recorded electronically in a laptop computer. Two diametrically opposite pairs of Demec points were fitted

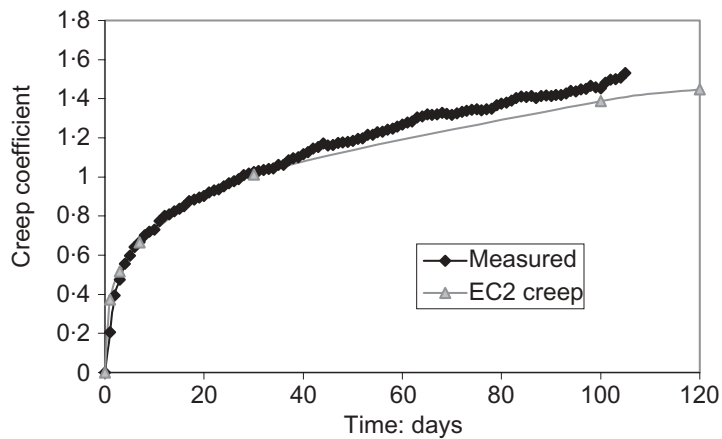

Fig. 6. Comparison of measured and predicted creep coefficients

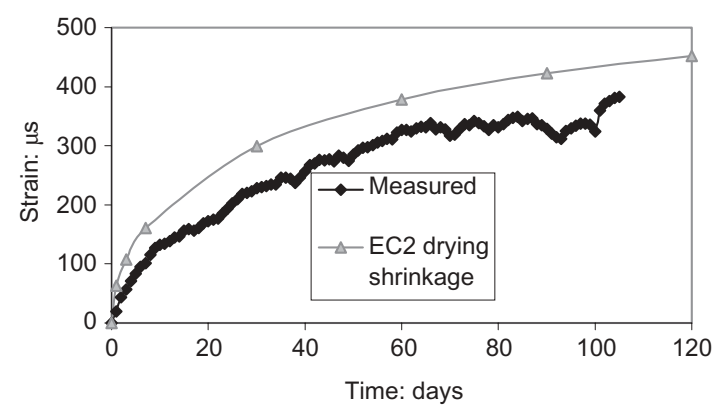

Fig. 7. Comparison of measured and predicted shrinkage strains

to each prop to eliminate the effect of bending. Three props of each type were tested at Imperial College to calibrate the Demec strain readings and determine the prop axial stiffnesses at the floor-to-floor height of $2.675 \mathrm{~m}$. The stiffnesses were estimated to be $29 \mathrm{kN} /$ $\mathrm{mm}$ for the Titan props and $16 \mathrm{kN} / \mathrm{mm}$ for the Acrow props.

It was not possible to establish the preload in all props since the props were installed before Imperial College researchers arrived on site. Therefore, the preload was measured in three backprops at each floor before slab 6 was cast. The preload varied between 6.7 $\mathrm{kN}$ and $22.5 \mathrm{kN}$ per backprop with an average of $\sim 12$ $\mathrm{kN}$ which corresponds to a uniformly distributed load of $1 \mathrm{kN} / \mathrm{m}^{2}$. For comparison, the average preloads in the backprops at Cardington (which were installed finger tight) were $8.3 \mathrm{kN}, 4.6 \mathrm{kN}$ and $5.8 \mathrm{kN}$ immediately before slabs 3,5 and 6 were cast corresponding to

Table 3. Estimated concrete cube strengths in slab at key construction stages

\begin{tabular}{l|c|c|c|c|c|c}
\hline \multirow{2}{*}{} & \multicolumn{3}{|c|}{ Striking } & \multicolumn{3}{c}{ At $w_{\text {peak }}$} \\
\cline { 2 - 7 } & Age: days & $f_{c}: \mathrm{MPa}$ & $f_{c t(\mathrm{Eq} 6)}: \mathrm{MPa}$ & Age: days & $f_{c}: \mathrm{MPa}$ & $f_{c t(\mathrm{Eq} 6)}: \mathrm{MPa}$ \\
\hline 3 & 9 & $33 \cdot 8$ & $2 \cdot 7$ & 12 & $36 \cdot 5$ & $2 \cdot 8$ \\
4 & 11 & $36 \cdot 3$ & $2 \cdot 8$ & 18 & $40 \cdot 6$ & $3 \cdot 0$ \\
5 & 5 & $29 \cdot 0$ & $2 \cdot 4$ & 10 & $36 \cdot 2$ & $2 \cdot 8$ \\
6 & 7 & $33 \cdot 9$ & $2 \cdot 7$ & 16 & $42 \cdot 1$ & $3 \cdot 1$ \\
\hline
\end{tabular}


uniformly distributed loads of $0 \cdot 6,0 \cdot 73$ and $0 \cdot 4 \mathrm{kN} / \mathrm{m}^{2}$ respectively.

Strains were measured in the backprops the day before and the day after casting the sixth floor slab during which time the mean ambient temperature fell by $6.5^{\circ} \mathrm{C}$ between strain measurements in the Titan props and by $9^{\circ} \mathrm{C}$ between strain measurements in the Acrow props. On the day before casting, the ambient temperature increased by $1^{\circ} \mathrm{C}$ during strain measurements in the Titan props and by $2^{\circ} \mathrm{C}$ during strain measurements in the Acrow props. The temperature did not vary significantly during strain measurements after casting. Backprop forces were calculated from the measured strains that were corrected to account for the temperature fall between measurements by subtracting the change in strain in an unloaded prop (see Table 4). The measured forces equal the increase in force due to casting the sixth floor slab $\left(w=6 \mathrm{kN} / \mathrm{m}^{2}\right)$ and the temperature drop.

Finite element analyses were carried out to estimate the change in backprop forces due to the combined effect of casting the supported slab and a temperature drop of $6 \cdot 5^{\circ} \mathrm{C}$. One half of floor plate shown in Fig. 4 was modelled with QD09 general shell and plate bending elements with nine nodes. Columns were modelled using 27 noded brick elements. Temperatures were not measured in the concrete columns but clearly lagged behind temperatures in the backprops due to greater thermal mass. Therefore, backprop forces were estimated (a) neglecting the temperature change (upper bound) and (b) assuming the temperature in the backprops fell $6 \cdot 5^{\circ} \mathrm{C}$ relative to that in the concrete (lower bound). The elastic modulus was assumed to be the same in all floors and was taken as either $(a) E_{c}=24$ $\mathrm{GPa}(C=1)$ or $(b) E_{c}=12 \mathrm{GPa}(C=0 \cdot 5)$. Table 4 shows that the measured and predicted forces agree well for backprops between floors 4 and 5 but it is not possible to determine which analysis is most realistic since the measured forces are probably only accurate to $+/-15 \%$. The analysis confirms that forces in backprops are relatively insensitive to $C$ if all slabs have the same stiffness and temperature effects are neglected.

Average construction loads were calculated for floors 3, 4 and 5 (in the bays in which backprop strains were measured) from the measured and predicted backprop forces with and without preload and temperature effects. The total load of the formwork, concrete and reinforcement in floor 6 was assumed to be $6.5 \mathrm{kN} / \mathrm{m}^{2}$. The preload was conservatively taken as $0.7 \mathrm{kN} / \mathrm{m}^{2}$ due to the high variability in measured preloads. The results are given in Table 5 which shows that the measured and predicted loads agree best for $C=0.5$ with $\Delta T=$ $-6 \cdot 5^{\circ} \mathrm{C}$. Table 5 also shows that the simplified method given in Table 3 of the Best Practice Guide ${ }^{10}$ (which is a refinement of equation (2)) gives conservative estimates of construction loads at St George Wharf. Analysis shows that $w_{\text {peak }}$ increases by only $4 \%$ if one level of backprops is used. Therefore, the author believes that deflections were not significantly reduced by using two levels of backprops at St George Wharf.

\section{Comparison of measured and predicted deflections measured at St Georges wharf}

Deflections were derived at the points indicated in Fig. 4 in floors 3-6 from levels taken on the top surface of the slab at the following stages where possible

(a) before and after striking

(b) before and after casting the slab directly above

(c) before and after striking the slab above

(d) before and after the backprops were finally removed

(e) after the backprops were finally removed

(f) between 90 to150 days under self weight.

Table 4. Measured and predicted forces in Titan backprops between floors 4 and 5 at St George Wharf

\begin{tabular}{|c|c|c|c|c|c|c|c|}
\hline \multirow{3}{*}{$\begin{array}{l}\text { Prop ref. } \\
\Delta T:{ }^{\circ} \mathrm{C}\end{array}$} & \multicolumn{7}{|c|}{ Backprop forces: $\mathrm{kN}$} \\
\hline & \multirow{2}{*}{$\frac{\text { Meas. }}{-6 \cdot 5}$} & \multicolumn{6}{|c|}{ Predicted by finite element analysis: $w=6 \mathrm{kN} / \mathrm{m}^{2}$} \\
\hline & & 0 & $-6 \cdot 5$ & 0 & $-6 \cdot 5$ & $-6 \cdot 5$ & $-6 \cdot 5$ \\
\hline C top & - & $0 \cdot 5$ & $0 \cdot 5$ & $1 \cdot 0$ & $1 \cdot 0$ & $0 \cdot 8$ & $0 \cdot 5$ \\
\hline $\mathrm{C}$ mid & - & $0 \cdot 5$ & $0 \cdot 5$ & $1 \cdot 0$ & $1 \cdot 0$ & $0 \cdot 8$ & $0 \cdot 8$ \\
\hline C bot & - & $0 \cdot 5$ & $0 \cdot 5$ & $1 \cdot 0$ & $1 \cdot 0$ & $0 \cdot 8$ & $0 \cdot 8$ \\
\hline $\mathrm{A} \& \mathrm{D}$ & $15 \cdot 15$ & $16 \cdot 42$ & $14 \cdot 90$ & $15 \cdot 55$ & $13 \cdot 09$ & $13 \cdot 74$ & $17 \cdot 33$ \\
\hline $\mathrm{B} \& \mathrm{C}$ & $27 \cdot 08$ & $23 \cdot 23$ & $22 \cdot 30$ & $21 \cdot 28$ & $19 \cdot 84$ & $20 \cdot 69$ & $23 \cdot 89$ \\
\hline $\mathrm{E}$ & $17 \cdot 92$ & $18 \cdot 82$ & $18 \cdot 70$ & $19 \cdot 88$ & $19 \cdot 60$ & $19 \cdot 60$ & $21 \cdot 61$ \\
\hline $\mathrm{F} \& \mathrm{G}$ & $28 \cdot 82$ & $26 \cdot 52$ & $24 \cdot 72$ & $23 \cdot 65$ & $21 \cdot 21$ & $22 \cdot 40$ & $26 \cdot 73$ \\
\hline $\mathrm{H} \& \mathrm{I}$ & $32 \cdot 85$ & $34 \cdot 73$ & $34 \cdot 08$ & $35 \cdot 77$ & $34 \cdot 18$ & $31 \cdot 61$ & $37 \cdot 94$ \\
\hline $\mathrm{J}$ & $25 \cdot 1$ & 34.99 & $32 \cdot 16$ & $27 \cdot 51$ & $23 \cdot 58$ & $26 \cdot 54$ & $34 \cdot 95$ \\
\hline $\mathrm{K}$ & $10 \cdot 68$ & $9 \cdot 31$ & $8 \cdot 17$ & $9 \cdot 41$ & $7 \cdot 46$ & $7 \cdot 84$ & $9 \cdot 27$ \\
\hline $\mathrm{L}$ & $10 \cdot 4$ & $10 \cdot 7$ & $9 \cdot 56$ & $10 \cdot 09$ & $8 \cdot 08$ & $8 \cdot 68$ & $10 \cdot 62$ \\
\hline M & $7 \cdot 03$ & $15 \cdot 79$ & $9 \cdot 24$ & $11 \cdot 75$ & $4 \cdot 14$ & $6 \cdot 19$ & $10 \cdot 21$ \\
\hline $\mathrm{N}$ & $18 \cdot 82$ & $20 \cdot 42$ & $18 \cdot 07$ & $15 \cdot 42$ & $8 \cdot 47$ & $16 \cdot 65$ & $19 \cdot 91$ \\
\hline Total force & $193 \cdot 85$ & $210 \cdot 93$ & $191 \cdot 89$ & $190 \cdot 31$ & $159 \cdot 64$ & $173 \cdot 94$ & $212 \cdot 45$ \\
\hline
\end{tabular}


Table 5. Measured and predicted construction loads at St George Wharf

\begin{tabular}{|c|c|c|c|c|c|c|c|}
\hline \multirow[t]{3}{*}{ Slab position } & & \multicolumn{6}{|c|}{ Load: $\mathrm{kN} / \mathrm{m}^{2}$} \\
\hline & & \multicolumn{2}{|c|}{ Measured } & \multicolumn{2}{|c|}{ Predicted } & \multirow{2}{*}{$\begin{array}{l}\text { Best Practice } \\
\text { Guide }\end{array}$} & \multirow{2}{*}{$\begin{array}{l}\text { Backprop to } \\
\text { ground } C=0.5\end{array}$} \\
\hline & & $C=0.5$ & $C=1$ & $C=0.5$ & $C=1$ & & \\
\hline \multirow{3}{*}{$\begin{array}{l}\text { No preload } \\
\Delta T=0\end{array}$} & Top & $9 \cdot 94^{\mathrm{a}}$ & $9 \cdot 80^{\mathrm{a}}$ & $9 \cdot 97$ & $10 \cdot 21$ & $10 \cdot 39$ & $9 \cdot 70$ \\
\hline & Middle & $7 \cdot 37^{\mathrm{a}}$ & $7 \cdot 46^{\mathrm{a}}$ & $7 \cdot 57$ & $7 \cdot 46$ & $7 \cdot 55$ & $8 \cdot 43$ \\
\hline & Bottom & $7 \cdot 19^{a}$ & $7 \cdot 24^{\mathrm{a}}$ & $6 \cdot 96$ & $6 \cdot 83$ & $6 \cdot 81$ & $6 \cdot 37$ \\
\hline & Top & $10 \cdot 17$ & $10 \cdot 17$ & $10 \cdot 19$ & $10 \cdot 58$ & - & - \\
\hline \multirow[t]{2}{*}{$\Delta T=-6 \cdot 5^{\circ} \mathrm{C}$} & Middle & $7 \cdot 27$ & $7 \cdot 27$ & $7 \cdot 47$ & $7 \cdot 27$ & - & - \\
\hline & Bottom & $7 \cdot 05$ & $7 \cdot 05$ & $6 \cdot 83$ & $6 \cdot 65$ & - & - \\
\hline \multirow{3}{*}{$\begin{array}{l}\text { With preload } \\
\Delta T=-6 \cdot 5^{\circ} \mathrm{C}\end{array}$} & Top & $9 \cdot 47$ & $9 \cdot 47$ & $9 \cdot 49$ & $9 \cdot 88$ & - & - \\
\hline & Middle & $7 \cdot 27$ & $7 \cdot 27$ & $7 \cdot 47$ & $7 \cdot 27$ & - & - \\
\hline & Bottom & $7 \cdot 75$ & $7 \cdot 75$ & $7 \cdot 53$ & $7 \cdot 35$ & - & - \\
\hline
\end{tabular}

${ }^{a}$ Measured backprop forces were increased by the predicted reduction in force due to $\Delta T=-6 \cdot 5^{\circ} \mathrm{C}$ with $C=0 \cdot 5$ or 1 as indicated.

The top and bottom surfaces of slabs three to six were inspected for cracking during and after construction. The most noticeable flexural cracking occurred at the columns and in the soffit of the bays between the circular columns. The cracks in the soffit were visible in good light from the slab below and were typically spaced between $200-400 \mathrm{~mm}$.

\section{Comparison of measured and predicted deflections}

Deflections were calculated in floor 6 (which was typical) at the key construction stages shown in Fig. 1 with Hossain's ${ }^{2}$ finite element program using a single step method in which $(a)$ the concrete tensile strength was taken as $f_{\text {ctmodified }}$ (see equation (1)) and $(b)$ an effective creep coefficient $\phi_{\text {eff }}$ (derived from superposition for the load history in Fig. 1) was used to account for the different ages at which loads were applied. Table 6 gives the parameters used in the analysis including loads which were taken as the measured values in Table 5 with preload. The concrete tensile strengths $f_{\text {ctmin }}$ and $f_{\text {ctmax }}$ in Table 6 are the values of $f_{\text {ctmodified }}$ (from stage $c$ onwards) corresponding to the minimum and maximum values of $f_{c t}$ at $w_{\text {peak }}$ in Table 3 of 2.8 and $3 \cdot 1 \mathrm{MPa}$ respectively. Creep coefficients were estimated using EC2 modified as described previously since the measured and predicted values were in good agreement. Drying shrinkage strains were also predicted using EC2. The single step method slightly underestimates deflections after unloading from $w_{\text {peak }}$ since it falsely implies deflections (neglecting shrinkage) reduce to zero on complete unloading. Therefore, deflections were increased after unloading from $w_{\text {peak }}$ using the Rotilio ${ }^{8}$ method which is illustrated in Fig. 2. The Rotilio ${ }^{8}$ increment in deflection due to a reduction in load $\Delta w$ is given by

$$
\delta a=0 \cdot 5\left(a_{\text {peak }}-a_{1}\right) \Delta w / w_{\text {peak }}
$$

where $a_{\text {peak }}$ is the short-term deflection under $w_{\text {peak }}$ with $\beta=0.5$ in $K_{\text {strike }}$ and $K_{\text {peak }}$ and $a_{1}$ is the shortterm deflection in the uncracked slab under $w_{\text {peak }}$. The maximum Rotilio increment was $1.6 \mathrm{~mm}$ which is insignificant in practice. The reloading line was assumed to follow the unloading line since $K_{\text {peak }}$ was always critical. Figs $8-12$ show that the author's method gives reasonable estimates of measured deflections (see Fig. 4 for locations of levelling points) but deflections are significantly underestimated if slabs are assumed uncracked. It is interesting to note that there was no significant recovery in deflection in the supporting slabs after striking. Deflections were also calculated at 150 days under self-weight with the mean 28 day concrete tensile strength intended in EC2 which was taken as $3.0 \mathrm{MPa}$ based on the design 28 day cylinder

Table 6. Loads and material properties used in analysis of deflections at St George Wharf

\begin{tabular}{|c|c|c|c|c|c|c|c|c|}
\hline Stage & $\begin{array}{l}\text { Stage ref in } \\
\text { Fig. } 1\end{array}$ & $\begin{array}{l}\text { Age: } \\
\text { days }\end{array}$ & $\begin{array}{c}E_{\text {ceff }}: \\
\mathrm{GPa}\end{array}$ & $\begin{array}{r}f_{c t m i n}: \\
\mathrm{MPa}\end{array}$ & $f_{\text {ctmax }}: \mathrm{MPa}$ & $w: \mathrm{kN} / \mathrm{m}^{2}$ & $\varepsilon_{s h}: \mu \mathrm{s}$ & $\beta$ \\
\hline Strike & $\mathrm{a}$ & 7 & $23 \cdot 0$ & $2 \cdot 7$ & $2 \cdot 7$ & 6 & 22 & 1 \\
\hline Just before casting slab above & $\mathrm{b}$ & 16 & $16 \cdot 3$ & $2 \cdot 7$ & $2 \cdot 7$ & 6 & 32 & $0 \cdot 5$ \\
\hline Just after casting slab above & $\mathrm{c}$ & 16 & $18 \cdot 5$ & $2 \cdot 8$ & 3 & $9 \cdot 5$ & 32 & 1 \\
\hline Just before striking slab above & $\mathrm{d}$ & 30 & $15 \cdot 6$ & $2 \cdot 8$ & 3 & $9 \cdot 5$ & 44 & $0 \cdot 5$ \\
\hline Just before backprops finally removed & $\mathrm{e}$ & 54 & $14 \cdot 2$ & $2 \cdot 3$ & $2 \cdot 5$ & $7 \cdot 8$ & 59 & $0 \cdot 5$ \\
\hline Just after backprops finally removed & $\mathrm{f}$ & 54 & $12 \cdot 4$ & $1 \cdot 8$ & 1.9 & 6 & 76 & $0 \cdot 5$ \\
\hline 90 days & - & 90 & $12 \cdot 2$ & $1 \cdot 8$ & $1 \cdot 9$ & 6 & 96 & $0 \cdot 5$ \\
\hline 150 days & - & 150 & $11 \cdot 5$ & $1 \cdot 8$ & 1.9 & 6 & 105 & $0 \cdot 5$ \\
\hline
\end{tabular}




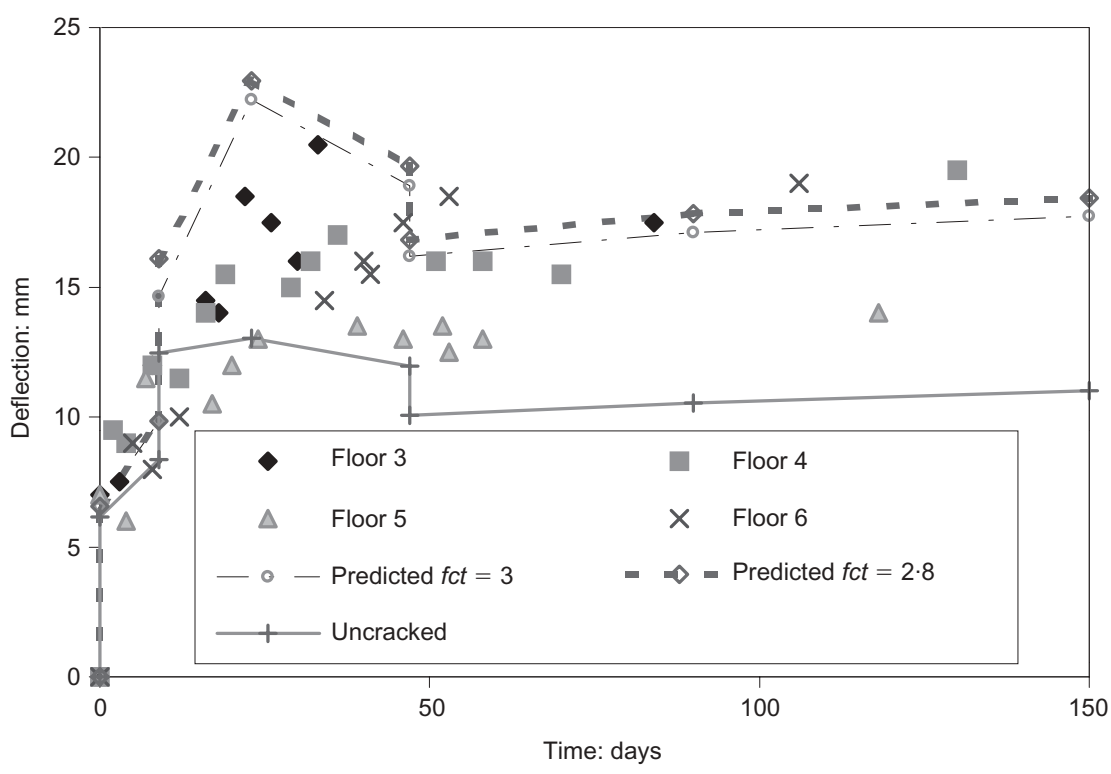

Fig. 8. Deflections at points 1 and 2 at St George Wharf

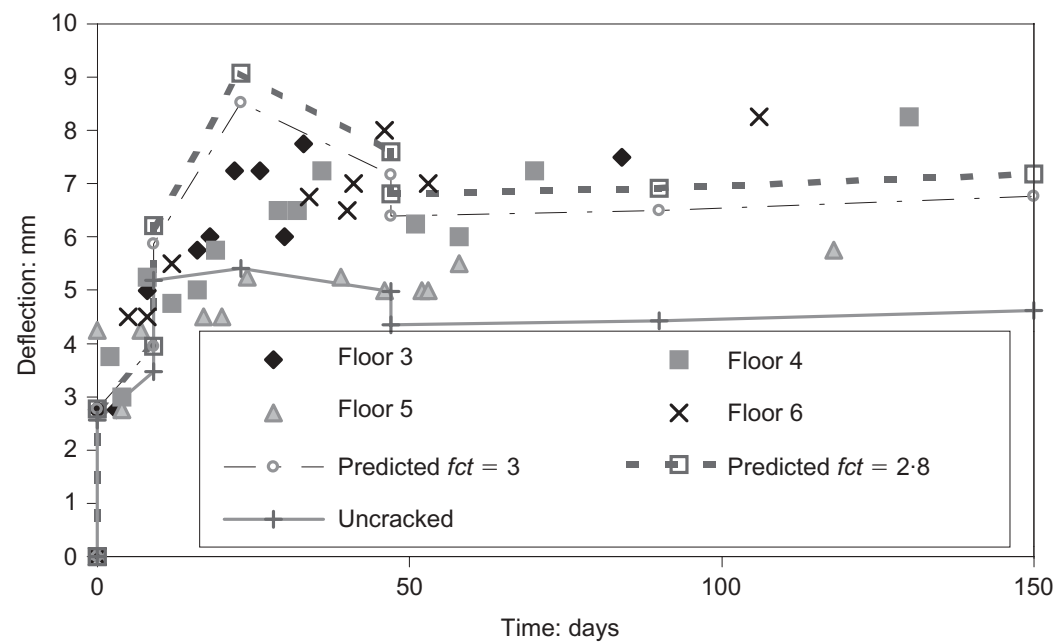

Fig. 9. Deflections at points 3 and 5 at St George Wharf

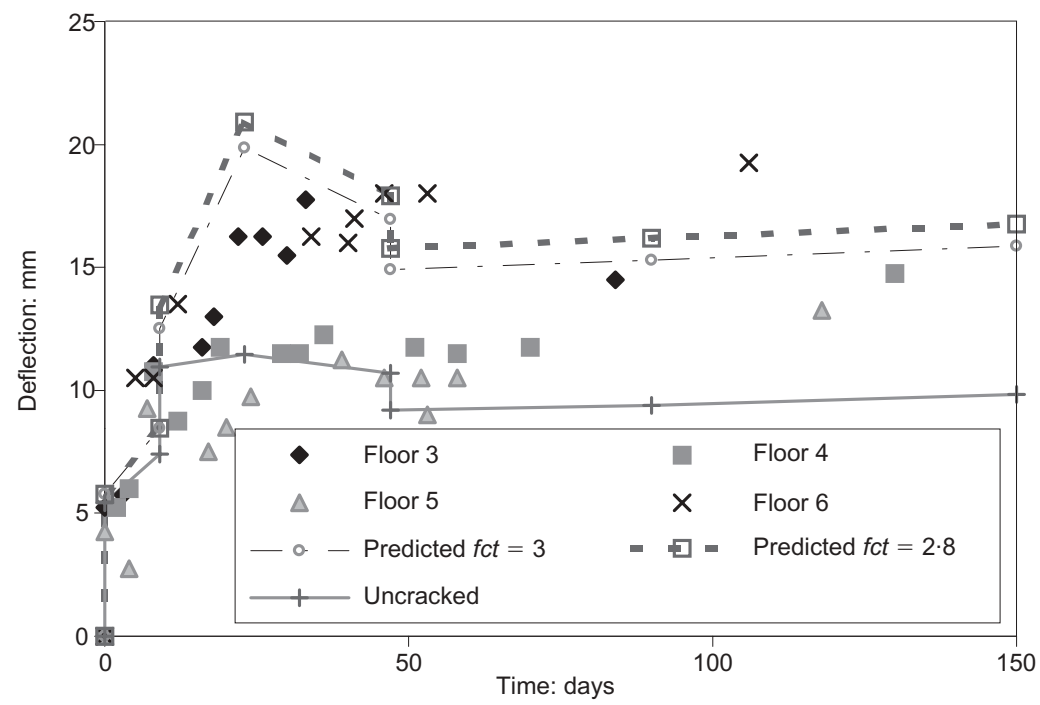

Fig. 10. Deflections at point 4 at St George Wharf

Magazine of Concrete Research, 2003, 55, No. 5 


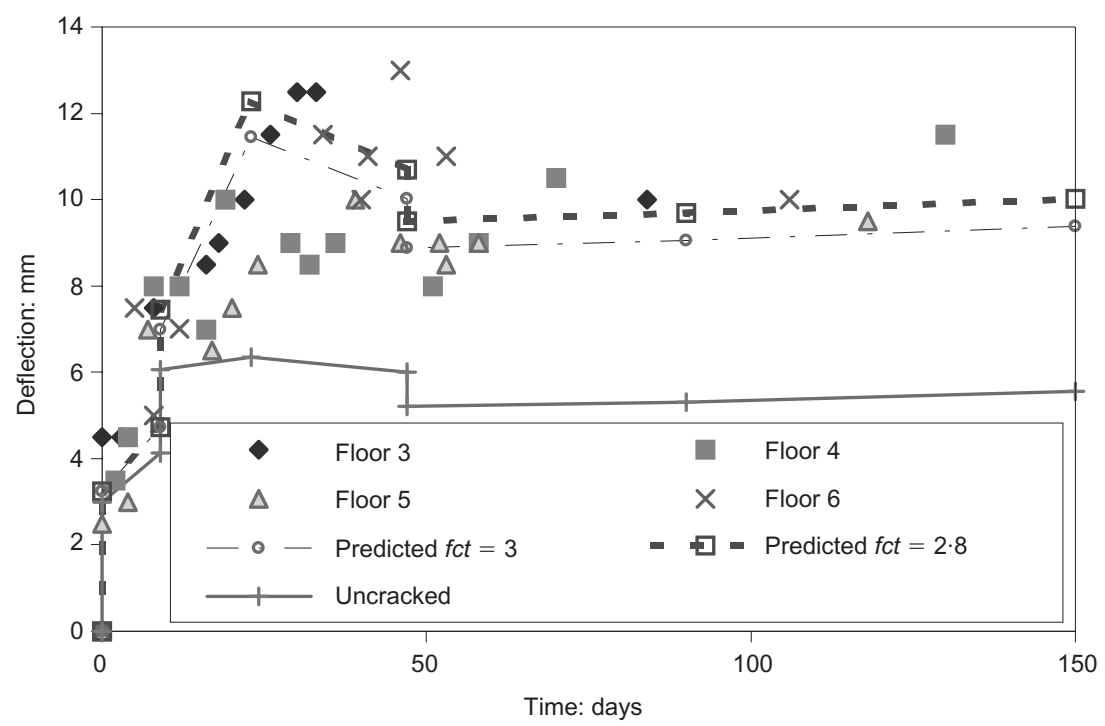

Fig. 11. Deflections at point 7 at St George Wharf

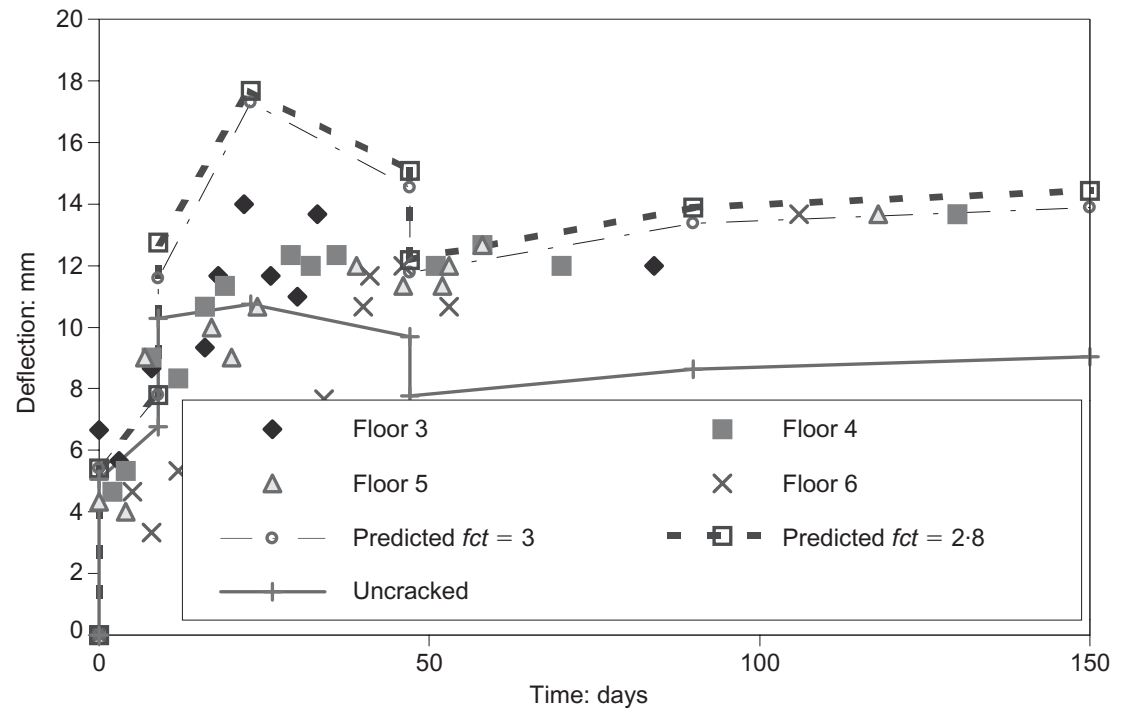

Fig. 12. Deflections at point 10 at St George Wharf

strength of $32 \mathrm{MPa}$. The resulting deflections were almost equal to those shown in Figs 8-12 for uncracked slabs and significantly less than measured.

The author's analysis predicts that the secant slope of the loading line from $w_{\text {strike }}$ to $w_{\text {peak }}$ was similar to that of the unloading line from $w_{\text {peak }}$ at St George Wharf which explains why good estimates were obtained for backprop forces if the same elastic modulus was used for all the slabs in the supporting assembly. A key difference between Cardington and St George Wharf is that $K_{\text {strike }}$ and $K_{\text {peak }}$ (both with $\beta=0.5$ ) were similar at Cardington since the slabs were struck very early. At St George Wharf, $K_{\text {peak }}$ (with $\beta=1$ ) was critical with the consequence that the loss in tension stiffening under $w_{\text {peak }}$ was greater than at Cardington. According to the author's analysis the average cracking factor in floor 5 reduced from $0 \cdot 8$ to $0 \cdot 5$ due to loss of tension stiffening between casting and striking floor 6 which caused a significant increase in backprop forces as illustrated in the last two columns of Table 4. Further test data are required to determine whether the predicted increase in backprop forces occurs in practice.

\section{Effect of propping to ground}

Deflections were similar in floor 3 to floors 4-6 even though the slab was propped to ground when the fourth floor was cast. Therefore, the effect of propping to ground was investigated with three levels of backprops arranged as for casting of floor 6. Slabs were assumed to carry their self-weight after striking. The 
top level of backprops was assumed to be Titan props and the bottom levels Acrow props. Prop forces were calculated assuming the slabs were cracked with $C=$ $0 \cdot 5$. Deflections reduced significantly when backprops were taken to ground but there was no significant increase in the backprop forces (see Table 5) which implies that there was little reduction in stress and hence cracking in the supporting slabs. This implies that the increase in deflections due to cracking under peak construction loads may not be significantly reduced as a result of propping to ground. This is borne out in practice in the third floor slab at St George Wharf which was propped to ground when the fourth floor was cast. In practice, the increase in backprop force due to propping to the ground would be less than in Table 5 since the backprop footings are not rigid as assumed in the analysis.

\section{Backprop forces from casting transfer slab}

The structure was unusual at St George Wharf since there was a $600 \mathrm{~mm}$ thick slab at floor 15 where the column grid changed. Stephenson's backprop design assumed that the load of the concrete in the $600 \mathrm{~mm}$ thick slab was shared equally between four slabs below which were each designed for an ultimate design load of $13.24 \mathrm{kN} / \mathrm{m}^{2}$. The slab is only buildable according to Beeby's approach ${ }^{5,10}$ if the backprops are preloaded. Backprops were provided on a 2.4 by $1.8 \mathrm{~m}$ grid. The top two levels of backprops were Ischebeck Titan props and the lowest level were steel Acrow props. Visual inspection showed the slabs to be slightly cracked after casting slab 15 but there was no sign of yielding of reinforcement. The author carried out three-dimensional finite element analysis to determine the prop forces in a typical $7.2 \mathrm{~m}$ square internal panel. The concrete elastic modulus was assumed to the same in all slabs and was taken as either $22 \mathrm{GPa}(C \sim 0 \cdot 8)$ or 11 GPa $(C \sim 0 \cdot 4)$. The sum of the backprop forces at each level and the corresponding uniformly distributed loads on each slab are given in Table 7 which shows that the top slab in the supporting assembly is predicted to be overloaded without preload in the props. In reality, the props were preloaded by being firmly hammered into position. The preload is not known but an average of $10 \mathrm{kN}$ per prop seems reasonable based on measurements before slab 6 was cast. Table 7 shows that preloading the backprops tends to even out loads between slabs and reduces $w_{\text {peak }}$ significantly. In theory, excessive preloading could overload of the lowest slab in the supporting assembly. This example shows that the simplified approach suggested in Table 3 of the Cardington Best Practice Guide on Early Striking and Improved Backpropping ${ }^{10}$ can be too conservative since it neglects the beneficial effects of preload and increasing the number and stiffness of backprops between floors.

\section{Conclusion}

The author obtained good estimates of backprop forces at Cardington and St George Wharf in elastic finite element analyses in which the concrete elastic modulus was reduced to account for cracking. This is significant since it supports the author's conclusion that long-term deflections in the Cardington slabs were governed by cracking during construction. Finite element analysis shows that forces in backprops typically only increase by around $10 \%$ if the concrete elastic modulus in each floor is reduced by a cracking factor of $C=$ $0 \cdot 5$. This explains why Beeby ${ }^{5}$ obtained good estimates of backprop forces at Cardington assuming slabs to be uncracked. The author's method for calculating the cracking factor $C$ is clearly too complex to be used in practice. Therefore, it is recommended that the elastic modulus should be taken as $0 \cdot 5 E_{\text {cpeak }}$ in all slabs when calculating forces in backprops using elastic analysis. This approach is reasonable since $(a)$ it gives good estimates of backprop forces at St George Wharf and Cardington and $(b)$ slabs crack before being overloaded redistributing load to the slabs below. Preload and temperature increases can increase forces in backprops significantly above values given by elastic analysis or Table 3 in the Best Practice Guide ${ }^{10}$ to values similar to those given by BS $5975 .^{8}$ For example, the maximum preload measured at St George Wharf was 22.5 $\mathrm{kN}$ which was similar to the average increase in force in the upper level of backprops due to casting floor 6 . In practice, the preload in backprops is usually unknown and variable. Therefore, there is a good case for continuing to use BS 5975 to calculate forces in backprops unless backpropping operations are carefully su-

Table 7. Average loads $\left(\mathrm{kN} / \mathrm{m}^{2}\right)$ from casting $600 \mathrm{~mm}$ thick slab at floor 15

\begin{tabular}{|c|c|c|c|c|c|}
\hline \multirow[t]{2}{*}{ Floor } & \multicolumn{2}{|c|}{$E_{c}=11 \mathrm{GPa}: C \sim 0.4$} & \multicolumn{2}{|c|}{$E_{c}=22 \mathrm{GPa}: C \sim 0.8$} & \multirow{2}{*}{$\begin{array}{l}\text { Table } 3^{\mathrm{a}} \text { Best } \\
\text { Practice Guide }\end{array}$} \\
\hline & No preload & Preload 10 kN/prop & No preload & Preload $10 \mathrm{kN} /$ prop & \\
\hline 14 & $12 \cdot 69$ & $10 \cdot 38$ & $13 \cdot 85$ & $11 \cdot 53$ & $15 \cdot 85$ \\
\hline 13 & $9 \cdot 53$ & $9 \cdot 53$ & $9 \cdot 47$ & $9 \cdot 47$ & $9 \cdot 48$ \\
\hline 12 & $8 \cdot 55$ & $8 \cdot 55$ & 8.07 & $8 \cdot 07$ & $7 \cdot 82$ \\
\hline 11 & $8 \cdot 13$ & $10 \cdot 45$ & $7 \cdot 51$ & $9 \cdot 82$ & - \\
\hline
\end{tabular}

a 2 levels of backprops. 
pervised on site to control preload and ensure backprops are placed where specified.

In the author's opinion, designers should recognise that slabs are subject to peak construction loads and design slabs accordingly. Table 3 in the Best Practice Guide $^{10}$ gives reasonable estimates of maximum possible peak construction loads for one or two levels of backprops. Construction of the $600 \mathrm{~mm}$ thick transfer slab showed that thick slabs can be supported during construction by thinner slabs below if backprops are closely spaced and preloaded to transfer load from the top slab in the supporting assembly.

The author's simplified method ${ }^{1-3}$ for taking account of cracking during construction in deflection calculations gave good estimates of deflections measured at $\mathrm{St}$ George Wharf. It is also shown that EC2 significantly underestimates deflections at St George Wharf since it neglects the effect of cracking during construction. Analysis suggests that backpropping to the ground may not reduce deflections significantly because peak construction loads are not greatly reduced.

\section{Acknowledgements}

This work was sponsored by the Department of Trade and Industry as part of the St George Case Study. The author gratefully acknowledges the assistance of Richard Moss at BRE, White Young Green, St George, Stephensons, Alan Tam of Imperial College and the Concrete Structures Laboratory at Imperial College. The views expressed in this paper are those of the author.

\section{References}

1. Vollum R. L, Moss R. M and HossainT. R. Slab deflections in the Cardington in-situ concrete frame building. Magazine of Concrete Research, 2002, 54, No. 1, 23-34.

2. Hossain T. R and Vollum R. L. Prediction of slab deflections and validation against cardington data. Proceedings of the Institution of Civil Engineers, Structures and Building, 2002, 152, No. 3, 235-248

3. Vollum R. L. Influences of shrinkage and construction loading on loss of tension stiffening in slabs. Magazine of Concrete Research, 2002, 54, No. 4, 273-282

4. Vollum R. L. and Hossain T. R. Are existing span to depth rules conservative for flat slabs? Magazine of Concrete Research, 2002, 54, No. 6, 411-421.

5. Beeby A. W. Early Striking of Formwork and Forces in Backprops, Construction Research Communications Report BR 394, 2000, pp. 106.

6. Comite Euro-International du Beton. CEB-FIP Model Code for Concrete Structures, Thomas Telford, London, 1990.

7. Beeby A. W. and ScotT R. H. Tension Stiffening of Concrete, Concrete Society Report 2nd Draft, 2002

8. Rotilio J.-D. Moment-curvature relationship. XIII FIP Congress and Exhibition, May 1998, The Netherlands.

9. British Standards Institution. Code of Practice for Falsework, BSI, London, 1996, BS 5975.

10. DETR. Best Practice Guide for In Situ Concrete Frame Buildings: Early Striking and Improved Backpropping, BCA, BRE, Construct, RCC, DETR, London, 2001

11. Bungey J. H., Soutsos M. N., Long A. E. and Henderson G. D. Early Age Acceptance of Concrete, BRE, London, 2000.

12. European Standard. Design of Concrete Structures, Part 1, General rules and Rules for Buildings, CEN, 2001, Eurocode 2.

13. Vollum R. L. Report into Construction Loading and Deflections at St George Wharf, report prepared for BRE, November 2002.

Discussion contributions on this paper should reach the editor by 1 April 2004 